\title{
Sanín Cano, Filólogo
}

$\mathbf{U}^{\mathrm{x}}$ No de los rasgos caracterizadores de la vida intelectual de Hispanoamérica, y quizá su tradición más firme y generalizada, es el de la constante atención que sus artistas, pensadores y políticos, y aun el hombre de la calle con preocupaciones de orden espiritual, han concedido siempre a las cuestiones del idioma, ya sean puramente gramaticales, ya las más complejas de la expresión literaria. No es, pues, un hecho accidental el que en el siglo pasado hayan sido hispanoamericanos los dos filólogos de más alta reputación del mundo hispánico: don Andrés Bello y don Rufíno José Cuervo, para no nombrar sino a los egregios.

Se ha querido ver la raíz de la tradición mencionada precisamente en el estímulo y resonancias que despertaron en la América española los trabajos de Bello. No cabe duda de que el magisterio del gran venezolano contribuyó a instaurar la todavía en su tiempo incipiente tradición, pero no es menos cierto que antes de hacerse sentir la influencia de Bello las cuestiones idiomáticas se planteaban ya como problemas que requerían soluciones meditadas. Es bien conocido el ejemplo de Echevetría, quien al intentar la elaboración de su teoría de una literatura de espíritu y estilo americanos, se vió arrastrado al planteamiento de la cuestión de la expresión literaria como primordial e ineludible.

Aun cuando el rasgo caracterizador arriba señalado puede descubrirse en toda América, quizá sea Colombia el país donde está más acusado, donde aquella tradición está más seguramente enraizada. Preocuparse por la propiedad y elegancia del español hablado y escrito y plantearse problemáticamente las cuestiones conexas con la expresión son disciplinas espirituales transformadas en hábitos que apenas hay hombre representativo de la cultura colombiana que 
no los haya practicado. No podía faltar entonces el nombre de don Baldomero Sanín Cano, uno de los más calificados mentores de dicha cultura desde hace ya más de medio siglo, en la copiosa bibliografía que Colombia ha echado al ruedo de la discusión americana de los problemas filológicos.

Para Sanín Cano, los problemas de la filología americana no son motivos ocasionales de escarceos amables, sino cuestiones fundamentales que afectan a la vida total del espíritu. Esta manera de plantearlos revela la profundidad de su interés y explica la persistente atención que les ha dedicado desde los días de su juventud.

No se liga el nombre de Sanín Cano a la dilucidación de ningún asunto ceñidamente teórico o técnico, y es lástima que así sea dado el vigor exigente de su formación en ambos aspectos, transparente en sus ensayos a pesar de su esfuerzo por disimularla. Parece más atraído por las cuestiones militantes de carácter general. Quizá porque de esa manera puede sustraerse mejor al aparato doctoral tan disonante con su espíritu.

Por eso tienen sus trabajos esa apariencia de levedad, de divulgación diríamos, si no tuviera esta palabra los peligros de sus concomitantes peyorativos, inevitables desde que la divulgación -noble servicio- se desdoró en manos de improvisadores adocenados.

Su gusto por el aire conversacional da a sus ensayos, graves por los temas, encanto y amenidad. Pero la impresión primeriza lograda por el primor de su arte de ensayista desaparece de inmediato porque no tarda el lector en percibir el pensamiento denso, fruto pulposo sazonado por la meditación prolongada donde hay mucho que morder y aprovechar.

El problema de la expresión americana es, según queda dicho, el tema capital de la filología de Sanín Cano. Se complace íntimamente su patriotismo hispanoamericano con el hecho de que nuestro español sea, con las inevitables diferencias, sensiblemente uniforme y que las fronteras políticas no impliquen fronteras lingüisticas. iQué grato el placer de viajar por las tierras de la América española, encontrarse siempre protegido por la cálida fraternidad de la lengua desde California a la Tierra del Fuego! : Qué abonado terreno para la difusión de los bienes de la cultura! El papel que la América nuestra desempeñará en el mundo del porvenir todos lo sentimos, será primordial tanto en lo cultural como en lo político y ello será posi- 
ble gracias a la fuerza que nos da la unidad de nuestra vida espiritual sustentada en la unidad de lengua.

¿Lo que acabamos de decir es aún profecía, es ya una realidad que estamos tocando con las manos? ¿No será que nuestros deseos y la satisfacción que de antemano nos prodice nos hace ver como una brillazón en la pampa, un espejismo que pronto no dejará de ser más que un triste recuerdo como toda perdida ilusión?

¿No está acaso allí agazapado el peligro cierto, que dramatizó Cuervo, de una fragmentación de la unidad idiomática de Hispanoamérica?

Ciertamente, ese peligro nos acechará permanentemente. De la historia de las lenguas conocidas, dice Sanín Cano, parece poder inferirse que la tendencia a la fragmentación es una tendencia constante. ${ }^{1}$ Pero además la lengua española de hoy, la que hablamos en Amiérica se va alterando sin que nadie lo pueda remediar; será dura tarea la del filólogo del porvenir que se ponga a determinar con fijeza cuándo murió la lengua castellana y a qué hora precisa vino a la luz el idioma de los argentinos, pongo por caso ...2

No se trata de sembrar el pánico reforzando sobre el tema que desazonó a Cuervo, ni de dejarse apresar por el pesimismo exangüe del "no hay qué hacer". Es simplemente la comprobación de un hecho natural. Los idiomas, nos recuerda Sanín Cano, una y otra vez, no alcanzan jamás estados permanentes, el cambio es la manifestación más segura, el pulso de su vivir. El idioma que deja de cambiar, que cesa de crearse a sí mismo año tras año, se anquilosa hasta quedar disecado, sin aliento vital en manos de piadosos conservadores.

No hay que perder entonces la serenidad ante la diaria comprobación de cambios en el español americano. La unidad lingüística de la América española no peligra por ello. $Y$ si algún día vemos que la tendencia antes señalada se transformara en movimiento, ello no sería más que un hecho naturàl nacido de circunstancias hoy. imprevisibles, y que, aun cuando dejaran de serlo, no estaría en nuestras manos dominar.

El cambio como hecho natural que prueba la ductilidad y potencia juvenil de nuestra lengua debe ser encauzado con inteligencia en su provecho, para hacer de ella un insustituíble instrumento del arte $\mathrm{y}$, por lo tanto, vehículo de nuestra unidad espiritual, que será 
poderosa en la medida en que cada uno de los pueblos de la América española se sienta representado en el arte de los demás.

El pensamiento lingüístico de Sanín Cano arraiga según se ve en el positivismo triunfante en los años de su formación intelectual, pero su fronda se mece en las cimas por donde circula el hábito más reciente y vivificador del idealismo.

El proceso de automodificación además es tan lento que puede ser contrapesado por otro proceso de tendencia unificadora provocado por la difusión de la cultura. "Se modifica sin duda -dice Sanín Cano del español hablado en América-, aunque los cambios ocurren con tal lentitud que estudiada [la lengua] en cortos periodos da la sensación de la permanencia. Sin embargo, el lenguaje de las proclamas con que los militares de principios del siglo [pasado] enardecían a las masas ya empieza a tener sabor anticuado y con ese carácter se gana la voluntad de los eruditos y mandarines. En el curso de pocos años la transformación no es fácil de precisar." 3

En las últimas líneas de este párrafo asoma lo que para Sanín Cano constituye la única amenaza cierta contra la unidad de nuestro español: el celo indiscreto de "eruditos y mandarines" a quienes el temor al magnificado peligro ha hecho perder la serenidad, extraviar el rumbo, puesto que dispuestos a contenerlo se han lanzado a luchar contra él con medidas no sólo inapropiadas sino contraproducentes, precipitando así la fragmentación que quieren evitar.

La conservación de nuestra unidad lingüística es, sin duda, una causa americana, y nadie puede desertar de ella puesto que en la unidad reside el futuro de nuestra significación en el mundo de la cultura.

En la lucha por asegurarla debemos poner a contribución todas nuestras fuerzas, pero no hay que olvidar que la fuerza más importante en cualquier lucha es la de la inteligencia. Sanín Cano combate con gran vigor, que no anula la gracia de la forma, a los "gramáticos y casticistas" que hacia fines del siglo pasado pulularon en nuestras provincias intelectuales -quedan aún hoy ejemplares rezagados- al calor de aplausos y distinciones que sus trabajos recibieron de sus cofrades españoles.

Con agudeza y sabiduría que no excluye el humor Sanín Cano sale airoso en su propósito de demostrar a sus adversarios que no han tomado la espada por la empuñadura sino por el filo. No los 
desdeña, todo lo contrario, les habla a la inteligencia porque los aprecia, porque considera que muchos de ellos han tomado el camino extraviado creyendo haber seguido el más directo. Reconoce que en general son competentísimos conocedores del castellano. Como prueba del respeto que le merecían, y la estimación, alli está el bello artículo recordatorio de Luis. Eduardo Villegas, "el último de los puristas". Hay en este homenaje una emoción velada y una pena profunda más que por la desaparición del viejo "hablista", dolor inevitable, por la inanidad de tanto fervor y trabajo por fijar y pulir su lenguaje. Lamenta que por la carencia de una doctrina lingǘstica el generoso esfuerzo de tantos redunde en perjuicio de la causa que creían servir. Es que estos Pedros Recios con el propósito de conservar la salud de la lengua juzgan mejor alimento que la nutritiva savia de la lengua popular el agua desvitalizada en que maceraron algunas viejas, ajadas, flores retóricas, y que mejor que exponerse al aire tostado que violento baja de las cumbres de las literaturas contemporáneas —que raja la piel y la oscurece pero renueva el vigor y agiliza la musculatura - era respirar el tufo guardado en las capillas de nuestro suntuoso panteón literario.

El resultado del tratamiento fué entecarla hasta el punto de dejarla sin vigor para trabajos de empeño. Sanín Cano dice sin eufemismos que "acaso la intransigencia de los gramáticos republicanos en favor del purismo sea la causa de la pobreza vocabular de la mayor parte de los escritores americanós..." 4 Pero nuestros puristas republicanos no hacían sino repetir las recetas que sus maestros monárquicos habían prescrito con los mismos resultados. " $\mathrm{El}$ español académico y universitario de nuestros días ${ }^{5}$ le viene a las mil maravillas el llamarlo decadente, carece de iniciativa y está encenagado en la imitación de los viejos modelos." 6

No renuncia Sanín Cano, con todo, a atraerlos al camino razonable. Pone para ello a contribución su extensa y moderna doctrina filológica y sus conocimientos amplísimos en el campo de la historia de las lenguas. Demuestra que ciertas lenguas dejaron de vivir precisamente por causa de puristas y gramáticos que lograron aislarlas de sus fuentes populares e impedir con ello su renovación. A los que hablan siempre de que las influencias extranjeras bastardean el carácter de la literatura nacional les recuerda que nunca fué más vigorosa la literatura española que después de sus nupcias con la 
literatura italiana y que la literatura tan nacional del gran siglo francés vivió bajo la sugestión de la literatura española.

En un vigoroso movimiento instintivo, de apetencia de vida, nuestra literatura logra por fin hacia fines del siglo pasado, liberarse de sus mandarines y patrones. $\mathrm{El}$ camino real está nuevamente encontrado. Sanín Cano, satisfecho puesto que fué uno de los guías más conscientes, explica el movimiento desde su punto de vista de filólogo diciendo: "Los escritores americanos empezaron a perderle el miedo al galicismo, se desentendieron un tanto del Diccionario de la Real Academia y se atrevieron a usar palabras del francés, del italiano, del inglés, y a conformarlas, no en la manera en que se usaban en otras lenguas sino adaptándolas a la índole de la nuestra..." 7 La discusión de Sanín Cano con los gramáticos tiene además otro aspecto positivo que es el del método que propone para llevar al español americano a transformarse en un excipiente sin par para la ciencia y la filosofía y en un instrumento plástico e insuperable para la expresión poética. Este método consiste primeramente en hacer que todo americano sienta como un ideal la necesidad de la comunidad de la lengua para hacer cierto el goce de las formas superiores de la cultura a todos los pueblos de nuestra América. Luego hay que evitar que nuestra heredad sea un hortus conclusus. Que nuestro huerto esté abierto a todos los vientos, que pasen por su meridiano todos los soles. El contacto con otras lenguas, la imitación de otras literaturas, no pueden bastardear las nuestras. Su hondo sentido de la historia le hace ver a Sanín Cano que con ello en vez de languidecer se fortalecerán hasta atreverse a emularlas y aún a lanzarse a atrevidas aventuras.

$Y$ menos aún hay que temer al habla popular: que la lengua literaria se nutra de ella, nada más eficaz contra la bastardía, ninguna fuente inspiradora más fecunda para el arte. "La lengua popular -dice Sanín Cano- es una cosa viva y chispeante, imagen de un pueblo, con cuyas vicisitudes se modifica, ya para enriquecerse con vocablos y nuevos modos de decir, ya para adaptarse a nuevas formas de cultura. En estas modificaciones queda siempre inalterado un fondo elemental, una base glotológica indefinible popularmente conocida con el nombre de genio del idioma." 8 
De este incorruptible genio del idioma son depositarios el pueblo en primer término y luego los artistas auténticos que son sus únicos intérpretes.

El pueblo y sus poetas crean su propio instrumento expresivo, no los gramáticos ni los filólogos. $\mathrm{Y}$ no es rica una lengua porque su diccionario registre muchos miles de palabras sino por el número de páginas no perecederas que produjeron sus artistas.

Hay además algunos trabajos que requieren realización inmediata. El primero es el de difundir las obras egregias entre el pueblo; éste no debe dudar de que la lengua de sus grandes intérpretes es la suya propia. A su vez los poetas deben estar atentos a las creaciones y expresiones populares de valor poético. En este orden de ideas, dice Sanín Cano que los escritores y poetas deben estar informados precisamente de estas cuestiones filológicas fundamentales.

Otro trabajo que no debe diferirse es el de unir estrechamente entre sí los centros intelectuales de los países de habla española, tarea no muy difícil si se piensa que por encima de los intereses materiales y las fronteras politicas hay un sentimiento popular de fraternidad continental que reposa más que en el pasado común en la hermandad del idioma, el que a su vez engendra ideales coincidentes, y hace sentirnos íntimamente solidarios en la realización de nuestro destino histórico común. Esta unión cuanto más estrecha, tanto más fecunda será para promover la unificación idiomática. E1 dỉa que una sola de las comunidades hispanoamericanas deje de reconocerse en el espejo de la lengua común, y que en esa comunidad aparezca un poeta que se exprese apoyándose en las divergencias de su lengua con la general porque así satisface los sentimientos de su pueblo, ese día el sentimiento de la comunidad de destino de los pueblos de habla española habrá empezado a desaparecer.

Felizmente ese peligro anunciado hace ya más de medio siglo como inmediato por algunos espíritus aprensivos, aún no parece inminente; sin embargo, está siempre latente. Debemos vivir apercibidos si queremos verle siempre alejado. Por último, cree Sanín Cano que deberíamos preocuparnos seriamente en la elaboración de "un Diccionario de la lengua usual de acuerdo con la ciencia moderna y capaz de satisfacer las necesidades lexicográficas de los que en este continente presumimos de hablar español". ${ }^{9}$ Para ello 
propone una reunión de filólogos americanos de reconocida competencia para planear e iniciar el trabajo, que debe tratar de hacerse con rapidez.

Esta tarea es urgente porque en el diccionario que todos manejamos, lo nuestro no está tratado con suficiente competencia. Esto no puede extrañarnos, pero sí nos extraña la condescendencia que se ha tenido para incluir en sus columnas tantos indigenismos, muchos de ellos desusados no solamente del español, pero aún de la lengua indígena de la que se dice ser originaria, condescendencia que contrasta con la rigurosa cuarentena que se impone a voces de uso generalizado en toda América y de eficacia expresiva en sus usos poéticos.

El diccionario proyectado debe ser, pues, usual y nada más para que su eficacia como instrumento unificador no quede en la buena intención. Sus páginas no deben pretender suplir al diccionario de indigenismos, ni tampoco al etimológico, ni menos a los de regionalismos. Debe recoger sí todas las voces vivas y difundidas por áreas considerables y sobre todo las que aparecen en las obras de nuestros buenos escritores y poetas.

Los poetas, con el pueblo, son los dueños del idioma y no se equivocan en aquello que el genio del idioma exige. Porque el genio del idioma es el germen en la semilla, es ese algo inexplicable que hace que la semilla no se equivoque jamás y reproduzca todos los caracteres esenciales de la planta que lleva dentro de sí, como todo poeta genial y todo escritor de talento son como semillas que llevan dentro el destino y los caracteres inalienables de su pueblo.

$$
* * * *
$$

La filología de Sanín Cano, pues, no es una filología de gabinete. Como todo saber fecundo está al servicio de ideales generosos y quiere compartirse cordialmente con el mayor número; para ello cuenta con la eficacia de una forma sin oropeles. Denso saber y forma leve, milagro posible solamente para quienes han logrado sorprender el secreto de la verdadera sabiduría.

Marcos A. Morínigo, University of Southern California. 


\section{$\mathrm{NOTAS}$}

1 Divagaciones filológicas y apólogos literarios. Manizales, Colombia (1934).

2 Divagaciones, pág. 20.

3 Divagaciones, pág. 91.

4 Divagaciones, pág. 43.

5 Se refiere Sanín Cano a los primeros años de este siglo.

6 Divagaciones, pág. 15.

7 Divagaciones, pág. 44.

8 Divagaciones, pág. 87.

9 Divagaciones, pág. 32. 
